\title{
Erratum: Estimating groundwater evapotranspiration rates using diurnal water-table fluctuations in a semi-arid riparian zone
}

\author{
Laura K. Lautz
}

Erratum to: Hydrogeology Journal (2008), 16:483-497 DOI 10.1007/s10040-007-0239-0

In the original paper an error was made in the calculation of potential evapotranspiration (PET) using the Priestley and Taylor (1972) equation. Measured values of daily shortwave radiation $\left(\mathrm{S}_{\mathrm{t}}, \mathrm{MJ} \mathrm{\textrm {m } ^ { - 2 }}\right)$ were used for the net radiation term $\left(R_{n}\right)$ in the original analysis. Net radiation is not equivalent to $S_{t}$, but rather is the sum of net shortwave $\left(S_{n}\right)$ and longwave $\left(\mathrm{L}_{\mathrm{n}}\right)$ radiation, which can be estimated based on $S_{t}$. Using raw measurements of $S_{t}$ (rather than estimating $R_{n}$ ) resulted in PET values that are larger than the true values. To correct this error, methods presented in Shuttleworth (1993) were used to estimate $S_{n}$ and $L_{n}$ based on the measured values of $S_{t}$.

Updated $R_{n}$ values were computed as $R_{n}=S_{n}+L_{n}$, where all radiation terms are in $\mathrm{MJ} \mathrm{m}^{-2}$. As stated in the original text, $\mathrm{S}_{\mathrm{t}}$ values in $\mathrm{MJ} \mathrm{m}{ }^{-2}$ were recorded at a NOAA Climate Reference Network station at the field site. Net shortwave radiation $\left(S_{n}\right)$ was derived from $S_{t}$ and estimates of the surface albedo ( $\alpha$, unitless) by $S_{n}=S_{t}(1-\alpha)$. An albedo of 0.25 was estimated based on the grass land cover. Net longwave radiation $\left(\mathrm{L}_{\mathrm{n}}\right)$ was estimated by $L_{n}=-f \in^{\prime} \sigma(T+273.2)^{4}$, where $f$ is a "cloudiness factor" (unitless), $\epsilon^{\prime}$ is estimated net emissivity (unitless), $\sigma$ is the Stefan-Boltzmann constant $\left(4.903 \times 10^{-9} \mathrm{MJ} \mathrm{m}^{-2}{ }^{\circ} \mathrm{K}^{-4}\right.$ day $\left.^{-1}\right)$ and $\mathrm{T}$ is average daily temperature $\left({ }^{\circ} \mathrm{C}\right)$. Cloudiness (f) represents the amount of incoming solar radiation received, relative to the maximum possible, given the latitude and time of year. Due to the arid climate, it was estimated as $f=1.35\left(S_{t} / S_{t o}\right)-0.35$, where $\mathrm{S}_{\text {to }}$ is the maximum possi-

Published online: 26 July 2008

(C) Springer-Verlag 2008

The online version of the original article can be found at http://dx. doi.org/100.1007/s10040-007-0239-0.

\section{K. Lautz (匹)}

Department of Forest and Natural Resources Management, SUNY College of Environmental Science and Forestry, 207 Marshall Hall, 1 Forestry Drive, Syracuse, NY 13210, USA e-mail: 1klautz@esf.edu

Tel.: +1-315-4704765

Fax: +1-315-4706535 ble solar radiation received at a given latitude on a given Julian day. Values of $f$ were limited to a range of 0 to 1 . Net emissivity $\left(\epsilon^{\prime}\right)$ between the atmosphere and the ground was approximated by $\epsilon^{\prime}=0.34+-0.14 \sqrt{e_{d}}$, where $e_{\mathrm{d}}$ is the saturated vapor pressure at the minimum observed daily temperature $(\mathrm{kPa})$. Temperature $(\mathrm{T})$ was measured in the field at the NOAA Climate Reference Network station.

The revised $R_{n}$ values were used in the Priestley-Taylor equation to obtain corrected PET values. The error was limited to a scaling effect on PET values and no groundwater evapotranspiration rates were affected. The corrected PET values were used to revise relevant figures and tables in the original text, which are given below (Figs. 7, 8, 9 and 11). This error does not change the nature of the discussion or conclusions. However, several values reported in the text of the original paper should be changed as follows (changes from original text are shown in bold):

On page 492, the last two sentences in the first column should be changed to: "PET is about $\mathbf{9} \mathbf{~ m m} / \mathbf{d a y}$ in June and mid-July, when the photoperiod is the longest, and decreases to less than $\mathbf{4} \mathbf{~ m m} / \mathbf{d a y}$ in late September and early October, as the number of daylight hours decreases. The peak PET rate was $9.9 \mathrm{~mm} / \mathbf{d a y}$ on 13 June 2005." In the second column on the same page, the end of the first paragraph should be changed to: "The total $\mathrm{ET}_{\mathrm{G}}$ at $\mathrm{W} 1$ over the entire period of observation was only about $\mathbf{2 8 \%}$ of the total PET and comparable to the total precipitation recorded. The total ETG at W2 over the entire period of observation was only about $2 \%$ of the total PET (Table 2)."

On page 495, under the heading Linkages between potential evapotranspiration and groundwater evapotranspiration, the first sentence of the second paragraph should be changed to: "The $\mathrm{K}_{\mathrm{c}, \mathrm{GW}}$ values computed in this study range from 0 to $\mathbf{7 2 \%}$ at $\mathrm{W} 1$ and 0 to $\mathbf{1 0 \%}$ at W2." The fourth sentence onwards of the third paragraph should be changed to: "Immediately following precipitation events $\left(>1 \mathrm{~mm} /\right.$ day), $\mathrm{K}_{\mathrm{c}, \mathrm{GW}}$ was between 10 and $\mathbf{2 5 \%}$ and increased to between 40 and $\mathbf{5 0 \%}$ over the several days following the precipitation event (Fig. 9)... On a biweekly basis at $\mathrm{W} 1$, the average $\mathrm{K}_{\mathrm{c}, \mathrm{GW}}$ fell to $\mathbf{2 5 \%}$ between 10 23 August, which corresponds to the biweekly period receiving the second highest precipitation rate during this study $(40.2 \mathrm{~mm})$. The 2 weeks before and after show higher average $\mathrm{K}_{\mathrm{c}, \mathrm{GW}}(\mathbf{3 5 \%})$, and much lower precipitation received during those periods $(5.4$ and $2.0 \mathrm{~mm}$, respectively)." 
Table 2 Biweekly averages (Avg.) and standard deviations (St. Dev.) for potential evapotranspiration (PET) and groundwater evapotranspiration $\left(\mathrm{ET}_{\mathrm{G}}\right)$ at $\mathrm{W} 1$ and $\mathrm{W} 2$

\begin{tabular}{|c|c|c|c|c|c|c|c|c|c|c|}
\hline \multirow[t]{3}{*}{ Biweekly Dates } & \multirow[t]{3}{*}{$\mathrm{n}$} & \multirow{2}{*}{\multicolumn{2}{|c|}{ PET (mm/d) }} & \multirow{2}{*}{\multicolumn{3}{|c|}{$\begin{array}{l}\mathrm{ET}_{\mathrm{G}, \mathrm{W} 1}(\mathrm{~mm} / \mathrm{d}) \\
\mathrm{S}_{\mathrm{y}}=7 \%\end{array}$}} & \multirow{2}{*}{\multicolumn{3}{|c|}{$\begin{array}{l}\mathrm{ET}_{\mathrm{G}, \mathrm{W} 2}(\mathrm{~mm} / \mathrm{d}) \\
\mathrm{S}_{\mathrm{y}}=7 \%\end{array}$}} & \multirow[t]{3}{*}{ Precipitation (mm) } \\
\hline & & & & & & & & & & \\
\hline & & Avg & St. Dev. & $\overline{\text { Avg }}$ & St. Dev. & $\begin{array}{l}\mathrm{ET}_{\mathrm{G}, \mathrm{W} 1} / \mathrm{PET} \\
\left(\mathrm{K}_{\mathrm{c}, \mathrm{GW}}\right)\end{array}$ & $\overline{\text { Avg }}$ & St. Dev. & $\begin{array}{l}\mathrm{ET}_{\mathrm{G}, \mathrm{W} 2} / \mathrm{PET} \\
\left(\mathrm{K}_{\mathrm{c}, \mathrm{GW}}\right)\end{array}$ & \\
\hline 18 May-6 June 2006 & 12 & 7.5 & 1.1 & 1.5 & 0.6 & 0.20 & & & & 11.3 \\
\hline 7 June-20 June 2006 & 12 & 7.8 & 1.3 & 2.9 & 1.0 & 0.37 & & & & 7.8 \\
\hline 13 July-26 July 2005 & 12 & 8.5 & 0.8 & 3.1 & 0.5 & 0.36 & 0.5 & 0.1 & 0.06 & 6.4 \\
\hline 27 July-9 August 2005 & 12 & 6.7 & 0.9 & 2.3 & 0.7 & 0.35 & 0.2 & 0.1 & 0.03 & 5.4 \\
\hline 10 August-23 August 2005 & 12 & 5.3 & 1.5 & 1.4 & 0.9 & 0.25 & 0.1 & 0.2 & 0.02 & 40.2 \\
\hline 24 August-6 September 2005 & 14 & 6.0 & 0.6 & 2.1 & 0.3 & 0.35 & 0.1 & 0.1 & 0.02 & 2.0 \\
\hline 7 September-20 September 2005 & 12 & 4.3 & 0.6 & 0.4 & 0.4 & 0.10 & 0.0 & 0.1 & 0.00 & 5.2 \\
\hline 21 September-8 October 2005 & 11 & 3.2 & 0.6 & 0.1 & 0.2 & 0.04 & 0.0 & 0.1 & 0.01 & 72.4 \\
\hline Average & 97 & 5.7 & 1.9 & 1.6 & 1.2 & 0.28 & 0.2 & 0.2 & 0.03 & \\
\hline Total (mm) & & 596.6 & & 168.4 & & 0.28 & 11.4 & & 0.02 & 150.7 \\
\hline
\end{tabular}

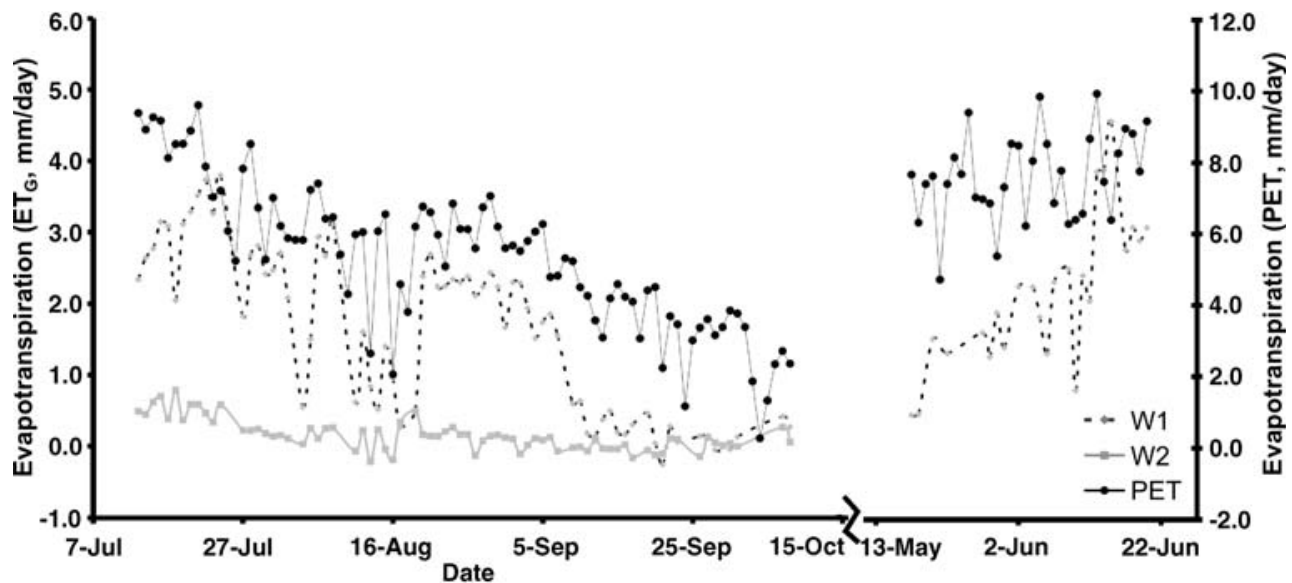

Fig. 7 Daily potential evapotranspiration (PET) and groundwater evapotranspiration $\left(\mathrm{ET}_{\mathrm{G}}\right)$ at $\mathrm{W} 1$ and $\mathrm{W} 2$ over the time period of this study (July-October 2005 and May-June 2006)

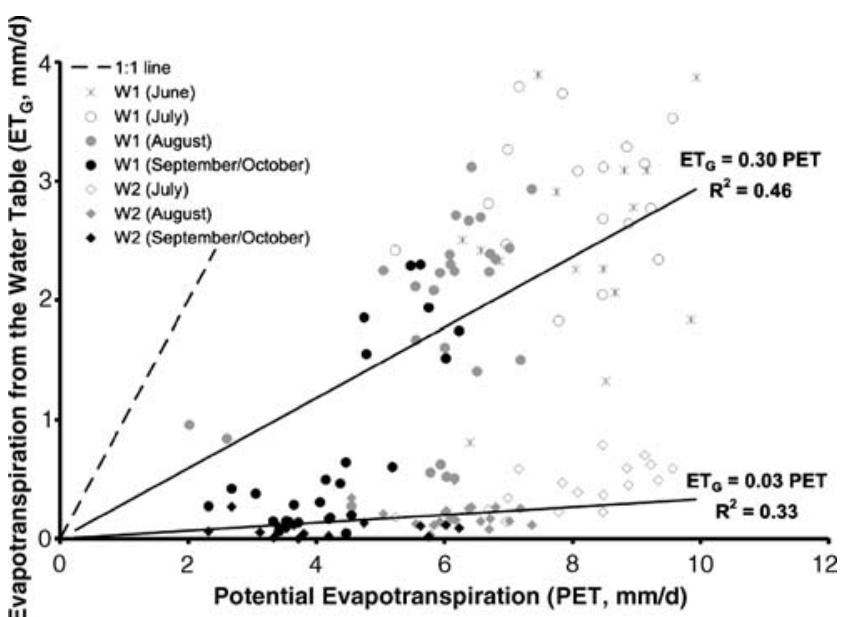

Fig. 8 Daily radiation-based potential evapotranspiration (PET) versus groundwater evapotranspiration $\left(\mathrm{ET}_{\mathrm{G}}\right)$ at $\mathrm{W} 1$ and $\mathrm{W} 2$. Linear regression lines are fit to all of the W1 or W2 data and forced through the origin. Coefficients in the regression equations are significantly different than zero with a $p$-value $<0.001$

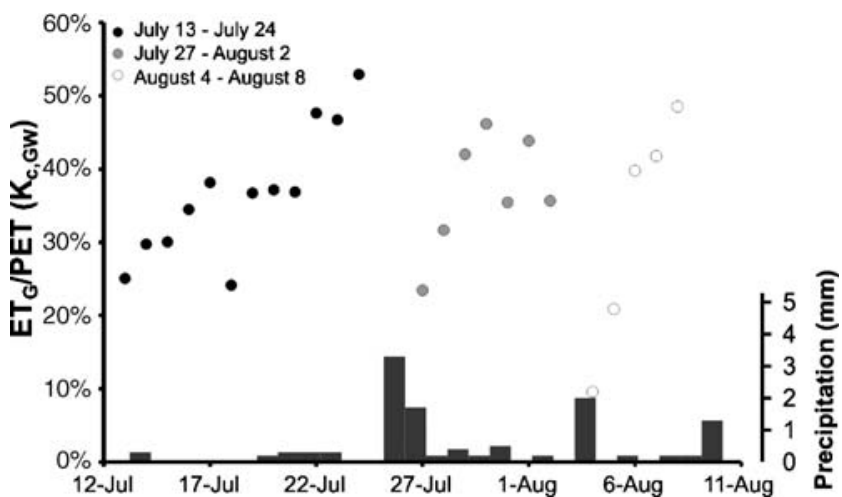

Fig. 9 The ratio of $\mathrm{ET}_{\mathrm{G}}$ to PET $\left(\mathrm{K}_{c, \mathrm{GW}}\right)$ over time between precipitation events (where the precipitation exceeded $1 \mathrm{~mm} /$ day) during July and early August 2005. Daily precipitation amounts are also shown 

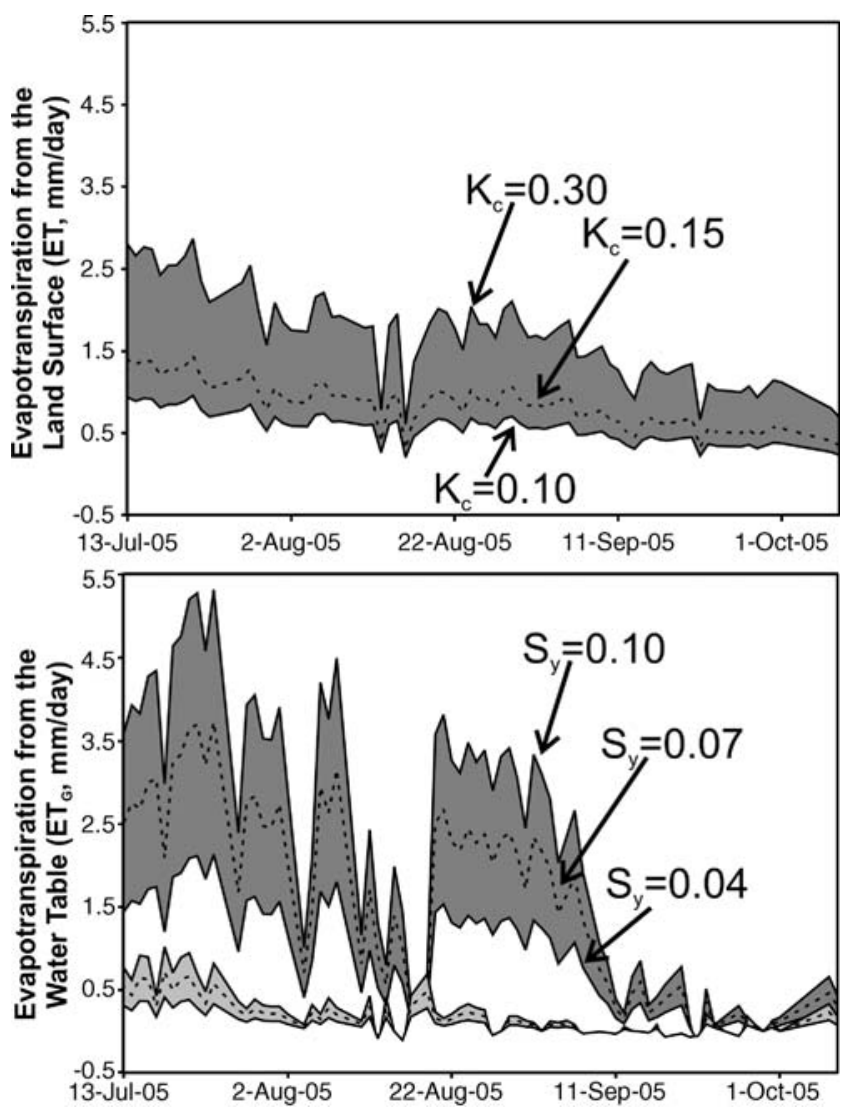

Fig. 11 Sensitivity analysis of evapotranspiration from the land surface $(\mathrm{ET})$ and from the water table $\left(\mathrm{ET}_{\mathrm{G}}\right)$ at $\mathrm{W} 1$ and $\mathrm{W} 2$. The $\mathrm{S}_{\mathrm{y}}$ values indicated for $\mathrm{W} 1$ are used for both $\mathrm{W} 1$ and W2. Dashed lines show the original values used in this study

\section{References}

Priestley CHB, Taylor RJ (1972) On the assessment of surface heat flux and evaporation using large scale parameters. Mon Weather Rev 100:31-92

Shuttleworth WJ (1993) Evaporation. In: Maidment DR (ed) Handbook of hydrology. McGraw-Hill, New York, pp 4.1-4.53 